\title{
Nonlocal Schrödinger Problem with Time Dependent Self-Adjoint Operator
}

\author{
Ali SIRMA* \\ *Haliç University, Department of Industrial Engineering Istanbul, Turkey \\ Orcid: 0000-0001-6114-2422
}

*Sorumlu Yazar e mail: alisirma@halic.edu.tr

Geliş Tarihi: 29.07 .2021

Kabul Tarihi: 16.09 .2021

Atıf/Citation: Sırma, A., "Nonlocal Schrödinger Problem with Time Dependent Self-Adjoint Operator", Haliç Üniversitesi Fen Bilimleri Dergisi 2021, 4/2: 111-122.

Araştırma Makalesi/ Research Article

\begin{abstract}
In this paper, in an arbitrary Hilbert space nonlocal boundary value problem for the Schrödinger equation with time dependent self-adjoint operator is studied. For the solution of this problem stability estimates are established. To find an approximate solution of nonlocal boundary value problem for the Schrödinger equation with time dependent self-adjoint operator the first order of accuracy Rothe difference scheme and the second order of accuracy Crank-Nicholson difference scheme are constructed. Stability estimates of these difference schemes have been obtained. To obtain stability estimates, the theory of spectral representation of self-adjoint operator is used. In order to support the theory, a numerical is given for the Schrödinger problem which is one dimensional in space variable, nonlocal in time variable and with a time dependent self-adjoint operator. A modified Gauss elimination method is used to solve these difference schemes.
\end{abstract}

Keywords: Modified Gauss elimination method, Self-adjoint operator, Stability.

\section{Zamana Bağlı Öz-Eşlenik Operatörlü Yerel Olmayan Schrödinger Problemi}

\section{Özet}

Bu makalede, zamana bağlı öz-eşlenik operatörlü Schrödinger denklemi için keyfi bir Hilbert uzayında yerel olmayan sınır değer problemi incelenmiştir. Bu problemin çözümü için kararlılık kestirimleri oluşturulmuştur. Yerel olmayan sınır değer 
probleminin zamana bağlı öz-eşlenik operatörlü Schrödinger denkleminin yaklaşık çözümünü bulmak için birinci doğruluk dereceli Rothe fark şeması ve ikinci doğruluk dereceli Crank-Nicholson fark şeması oluşturulmuştur. Bu fark şemalarının kararlılık kestirimleri elde edilmiştir. Kararlılık kestirimlerini elde edebilmek için öz eşlenik operatörlerin spektral temsil teorisi kullanılmıştır. Teoriyi desteklemek için uzay değişkenine göre bir boyutlu, zamana göre lokal olmayan, zamana bağlı özeşlenik operatörlü Schrödinger problemi için sayısal bir örnek verilmiştir. Fark şemalarının çözümünü bulmak için modifiye edilmiş Gauss eleme metodu kullanılmıştır.

Anahtar Kelimeler: Modifiye edilmiş Gauss eleme yöntemi, Öz-eşlenik operatör, Kararlil1k.

\section{Introduction}

Schrödinger equation with time dependent operator or with time dependent Hamiltonian has many application in quantum mechanics and chemistry, as a few example about these applications and for some studies about Schrödinger equation with time dependent Hamiltonian, references [1-4] and references therein can be searched. In this work, in a Hilbert space $H$ with the time dependent self-adjoint operator $A(\mathrm{t})$, the Schrödinger equation

$$
i \frac{d u}{d t}+A(t) u=f(t), \quad 0<t<T
$$

with the nonlocal boundary condition at the multiple finite points

$$
u(0)=\sum_{m=1}^{p} \alpha_{m} u\left(\lambda_{m}\right)+\varphi, 0<\lambda_{m}<\lambda_{m}<\cdots<\lambda_{m} \leq T
$$

is considered. Ashyralyev and Sirma in [5] studied the abstract Schrödinger equation (1) with nonlocal boundary condition (2) but with a time independent self-adjoint operator $A$.

The aim of this study is to generalize the work in [5] to a time dependent self-adjoint operator. Following [5], here also existence and uniqueness of solution of equation (1) with a nonlocal boundary condition (2) are obtained. Stability estimate of it is investigated. To obtain approximate solution of a Schrödinger equation with a time dependent self-adjoint operator (1) and with nonlocal boundary conditions (2), 
first order of accuracy Rothe difference scheme and second order of accuracy Crank-Nicholson difference scheme are constructed. Stability estimates of these difference schemes are investigated. At the last part in one dimension in space variable a numerical example is given.

\section{Material and Method}

Theorem 1: Assume that $\sum_{m=1}^{p}\left|\propto_{m}\right|<1$, then there exists a unique solution $u(t)$ of problem (1)-(2) and the following stability inequality is satisfied:

$$
\max _{0<t<T}\|u(t)\|_{H} \leq\left(1+C\left(\propto_{1}, \ldots, \propto_{p}\right)\right)\left[\|\varphi\|_{H}+T \max _{0<t<T}\|f(t)\|_{H}\right] .
$$

Proof: First, a formula for the solution of the problem (1)-(2) is obtained. For the smooth data of problem

$$
i \frac{d u}{d t}+A(t) u=f(t), 0<t<T, u(0)=\vartheta
$$

there exists a unique solution of the problem (4) in the form

$$
u(t)=e^{i \int_{0}^{t} A(s) d s} u(0)-i \int_{0}^{t} e^{i \int_{s}^{t} A(\gamma) d \gamma} f(s) d s .
$$

Then, using the nonlocal boundary condition (2) we get

$$
u(0)=\sum_{m=1}^{p} \alpha_{m} e^{i \int_{0}^{\lambda_{m}} A(s) d s} u(0)-i \sum_{m=1}^{p} \alpha_{m} \int_{0}^{\lambda_{m}} e^{i \int_{s}^{\lambda_{m}} A(\gamma) d \gamma} f(s) d s+\varphi .
$$

Since $\left\|e^{i i_{0}^{\lambda_{m}} A(s) d s}\right\|_{H} \leq 1$ and $\sum_{m=1}^{p}\left|\alpha_{m}\right|<1$, then the operator $I-\sum_{m=1}^{p} \alpha_{m} e^{i \int_{0}^{\lambda_{m}} A(s) d s}$ has an inverse $R=\left(I-\sum_{m=1}^{p} \alpha_{m} e^{i \int_{0}^{\lambda_{m}} A(s) d s}\right)^{-1}$ and $\|R\| \leq C\left(\propto_{1}, \ldots, \propto_{p}\right)$. Since $\left\|e^{i \int_{0}^{\lambda_{m}} A(s) d s}\right\|_{H} \leq 1$, by following Ashyralyev and Sirma [5] the result is obtained.

Now, in order to obtain an approximate solution of the nonlocal boundary value problem for the Schrödinger equation with time 
dependent operator (1)-(2), the corresponding first order Rothe difference scheme

$$
\begin{aligned}
& i \frac{u_{k}-u_{k-1}}{\tau}+A_{k} u_{k}=\varphi_{k}, \quad \varphi_{k}=f\left(t_{k}\right), \quad t_{k}=k \tau, \quad 1 \leq k \leq N, N \tau=T, \\
& u_{0}=\sum_{m=1}^{p} \alpha_{m} u_{l_{m}}+\varphi,
\end{aligned}
$$

is associated. Here $l_{m}=\left[\frac{\lambda_{m}}{\tau}\right]$, greatest integer part of $\frac{\lambda_{m}}{\tau}$. Using induction, the solution of (7) with initial condition $u_{0}=\vartheta$ for the approximate solution of (4) is obtained as

$$
u_{k}=\left(\prod_{j=1}^{k} R_{j}\right) u_{0}-i \tau \sum_{j=1}^{k}\left(\prod_{i=1}^{k-j+1} R_{i}\right) \varphi_{j}, \quad 1 \leq k \leq N
$$

Here for $1 \leq k \leq N, R_{k}=\left(I-i \tau A_{k}\right)^{-1}$. Using the formula (9) and the nonlocal condition (8) the formula

$$
u_{0}=\sum_{m=1}^{p} \alpha_{m}\left(\prod_{j=1}^{l_{m}} R_{j}\right) u_{0}-i \tau \sum_{m=1}^{p} \alpha_{m} \sum_{j=1}^{l_{m}}\left(\prod_{i=1}^{l_{m}-j+1} R_{i}\right) \varphi_{j}+\varphi
$$

is obtained. Since for any $1 \leq j \leq l_{m}$ the norm of $R_{j}$ is less or equal than 1 and by assumption $\sum_{m=1}^{p}\left|\alpha_{m}\right|<1$ then the norm of $\sum_{m=1}^{p} \alpha_{m}\left(\Pi_{j=1}^{l_{m}} R_{j}\right)$ is less than 1 , then the operator $I-\sum_{m=1}^{p} \alpha_{m}\left(\Pi_{j=1}^{l_{m}} R_{j}\right)$ has an inverse $T_{\tau}=\left(I-\sum_{m=1}^{p} \alpha_{m}\left(\Pi_{j=1}^{l_{m}} R_{j}\right)\right)^{-1}$. Therefore for the initial value the formula

$$
u_{0}=T_{\tau}\left(-i \tau \sum_{m=1}^{p} \alpha_{m} \sum_{j=1}^{l_{m}}\left(\prod_{i=1}^{l_{m}^{-j+1}} R_{i}\right) \varphi_{j}+\varphi\right)
$$

holds. So, for the solution of Rothe difference scheme (7)-(8), the following formula is achieved:

$$
u_{k}=\left\{\begin{array}{c}
u_{k}=\left(\prod_{j=1}^{k} R_{j}\right) u_{0}-i \tau \sum_{j=1}^{k}\left(\prod_{i=1}^{k-j+1} R_{i}\right) \varphi_{j}, \quad 1 \leq k \leq N, \\
T_{\tau}\left(-i \tau \sum_{m=1}^{p} \alpha_{m} \sum_{j=1}^{l_{m}}\left(\prod_{i=1}^{l_{m}-j+1} R_{i}\right) \varphi_{j}+\varphi\right), k=0 .
\end{array}\right.
$$

Now in order to obtain an approximate solution of the problem (1)-(2), let us associate this problem (1)-(2) with the corresponding Crank-Nicholson difference scheme. But obtaining Crank-Nicholson 
difference scheme a little more work is needed. So it is better to explain how it is obtained. In order to obtain second order of accuracy Crank-Nicholson difference scheme, consider the equation (1) at the point $t=t_{k}-\frac{\tau}{2}$

$$
i \frac{d u}{d t}\left(t_{k}-\frac{\tau}{2}\right)+A\left(t_{k}-\frac{\tau}{2}\right) u\left(t_{k}-\frac{\tau}{2}\right)=f\left(t_{k}-\frac{\tau}{2}\right), \quad 0<t<T .
$$

The derivative $\frac{d u}{d t}\left(t_{k}-\frac{\tau}{2}\right)$ can be approximated with a second order accuracy central difference scheme of step size $\frac{\tau}{2}$ and using the Taylor expansion $u\left(t_{k}\right)$ and $u\left(t_{k-1}\right)$ about the point $t=t_{k}-\frac{\tau}{2}, u\left(t_{k}-\frac{\tau}{2}\right)$ can be approximated by $\frac{u\left(t_{k}\right)+u\left(t_{k-1}\right)}{2}$, which is second order. Denoting $A\left(t_{k}-\frac{\tau}{2}\right)$ by $A_{k-\frac{1}{2}}$ and an approximation of $u\left(t_{h}\right)$ by $u_{k}$ the equation (13) can be approximated by

$$
i \frac{u_{k}-u_{k-1}}{\tau}+A_{k-\frac{1}{2}}\left(\frac{u_{k}+u_{k-1}}{2}\right)=\varphi_{k}, \quad \varphi_{k}=f\left(t_{k-\frac{1}{2}}\right), \quad t_{k}=k \tau, \quad 1 \leq k \leq N, \quad N \tau=T .
$$

In order to approximate the multipoint nonlocal boundary condition (2), the case of whether $l_{m}=\left[\frac{\lambda_{m}}{\tau}\right]$, greatest integer part of $\frac{\lambda_{m}}{\tau}$ is an integer or not should be analyzed. If $l_{m}$ is an integer, which is an straight forward case, the value $u\left(l_{m}\right)$ is taken. But if $l_{m}$ is not an integer, $u\left(\lambda_{m}\right)$ is approximated by $\frac{1}{2}\left(u_{l_{m}}+u_{l_{m+1}}\right)$. Nevertheless to obtain second order approximation, until second derivative Taylor expansion should be obtained. First derivative in that Taylor expansion will be replaced by the expression achieved by equation (13). Of course here it is assumed that $u(t)$ has a continuous second derivative on the corresponding interval. Hence in order to get approximation of nonlocal boundary condition (2), the expression

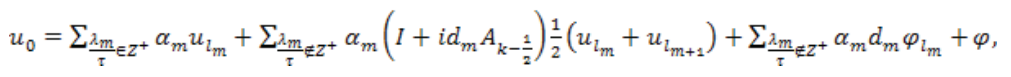


is used. Here, $l_{m}=\left[\frac{\lambda_{m}}{\tau}\right]$ and $d_{m}=\lambda_{m}-l_{m} \tau-\frac{\tau}{2}$. Hence for the second order of accuracy Crank-Nicholson difference scheme to obtain approximate solution of (1)-(2), the formulas (14)-(15) is achieved. In order to obtain a formula for the solution of (14)-(15), induction is used and the expression

$$
u_{k}=\left(\prod_{j=1}^{k} B_{j}\right) u_{0}-i \tau \sum_{j=1}^{k}\left(\prod_{i=j+1}^{k} B_{i}\right) C_{j} \varphi_{j}, \quad 1 \leq k \leq N,
$$

is obtained. Here, whenever lower index is greater than upper index in product, the result of product is taken as identity. Here $C_{k}=\left(I-i \frac{\tau}{2} A_{k-\frac{1}{2}}\right)^{-1}$ and $B_{k}=\left(I+i \frac{\tau}{2} A_{k-\frac{1}{2}}\right) C_{k}$.

In order to find $u_{0}$, using formula (16) and the condition (14) the expression

$$
\begin{aligned}
& u_{0}=\sum_{\frac{\lambda_{m}}{\tau} \in Z^{+}} \alpha_{m}\left(\prod_{j=1}^{l_{m}} B_{j}\right) u_{0}-i \tau \sum_{\frac{\lambda m_{E Z^{+}}}{\tau}} \alpha_{m} \sum_{j=1}^{l_{m}}\left(\prod_{i=j+1}^{l_{m}} B_{i}\right) C_{j} \varphi_{j}+\sum_{\frac{\lambda_{m} Z^{+}}{\tau}} \alpha_{m}(I+ \\
& \left.i d_{m} A_{k-\frac{1}{2}}\right) \frac{1}{2}\left(\prod_{j=1}^{l_{m}} B_{j}\right) u_{0}-i \tau \sum_{\frac{\lambda_{m}}{\tau} Z^{+}} \alpha_{m}\left(I+i d_{m} A_{k-\frac{1}{2}}\right) \frac{1}{2} \sum_{j=1}^{l_{m}}\left(\prod_{i=j+1}^{l_{m}} B_{i}\right) c_{j} \varphi_{j}+ \\
& \sum_{\frac{\lambda_{m}}{\tau} \notin Z^{+}} \alpha_{m}\left(I+i d_{m} A_{k-\frac{-1}{2}}\right) \frac{1}{2}\left(\Pi_{j=1}^{l_{m}+1} B_{j}\right) u_{0}-i \tau \sum_{\frac{\lambda m_{m}}{\tau} \notin Z^{+}} \alpha_{m}(I+ \\
& \left.i d_{m} A_{k-\frac{1}{2}}\right) \frac{1}{2} \sum_{j=1}^{l_{m}+1}\left(\Pi_{i=j+1}^{l_{m}+1} B_{i}\right) C_{j} \varphi_{j}-i \sum_{\frac{\lambda_{m} Z^{+}}{\tau}} \alpha_{m} d_{m} \varphi_{l_{m}}+\varphi \text {, }
\end{aligned}
$$

is achieved. For each $k$, by using spectral representation of self-adjoint operators it is easy to show that the norm of $C_{k}$ is strictly less than 1 but the norm of $B_{k}$ and the norm of $\left(I+i d_{m} A_{k-\frac{1}{2}}\right) \frac{1}{2}\left(I+B^{l_{m}+1}\right)$ are less or equal than 1. By using the assumption $\sum_{m=1}^{p}\left|\alpha_{m}\right|<1$ also, existence of $T_{\tau}$ which is the inverse of the operator

$$
I-\sum_{\frac{\lambda_{m}}{\tau} \in Z^{+}} \alpha_{m}\left(\prod_{j=1}^{l_{m}} B_{j}\right)-\sum_{\frac{\lambda_{m}}{\tau} \notin Z^{+}} \alpha_{m}\left(I+i d_{m} A_{k-\frac{1}{2}}\right) \frac{1}{2}\left(I+B^{l_{m}+1}\right)\left(\Pi_{j=1}^{l_{m}} B_{j}\right),
$$

can be shown. Hence for the approximation of the initial value the formula

$$
\begin{aligned}
& u_{0}=T_{\tau}\left(-i \tau \sum_{\frac{\lambda_{m}}{\tau} \in Z^{+}} \alpha_{m} \sum_{j=1}^{l_{m}}\left(\prod_{i=j+1}^{l_{m}} B_{i}\right) c_{j} \varphi_{j}--i \tau \sum_{\frac{\lambda_{m}}{\tau} Z^{+}} \alpha_{m}(I+\right. \\
& \left.i d_{m} A_{k-\frac{1}{2}}\right) \frac{1}{2} \sum_{j=1}^{l_{m}}\left(\Pi_{i=j+1}^{l_{m}} B_{i}\right) c_{j} \varphi_{j}-i \tau \sum_{\frac{a_{m}}{\tau} \notin Z^{+}} \alpha_{m}\left(I+i d_{m} A_{k-\frac{1}{2}}\right) \frac{1}{2} \sum_{j=1}^{l_{m}^{m+1}}\left(\Pi_{i=j+1}^{l_{m}+1} B_{i}\right) C_{j} \varphi_{j}- \\
& \left.i \sum_{\frac{\lambda_{m}}{\tau} \notin Z^{+}} \alpha_{m} d_{m} \varphi_{l_{m}}+\varphi\right) \text {, }
\end{aligned}
$$


is achieved. So that for the solution of Crank-Nicholson difference scheme (14)-(15), the formulas (16) and (19) are obtained.

Theorem 2: Assume that $\sum_{m=1}^{p}\left|\propto_{m}\right|<1$, then the solutions of the difference schemes (7)-(8) and (14)-(15) obey the following stability inequality:

$$
\max _{0<k<N}\left\|u_{k}\right\|_{H} \leq\left(1+C\left(\propto_{1}, \ldots, \propto_{p}\right)\right)\left[\|\varphi\|_{H}+T \max _{1<k<N}\left\|\varphi_{k}\right\|_{H}\right] .
$$

Using spectral representation of self-adjoint operators and using the results obtained above, by following [5], the theorem can easily be proved.

Now, in order to show applicability of the theory obtained until now, a numerical example will be given. Consider one dimensional in space Schrödinger equation with time-dependent self-adjoint operator and with nonlocal boundary condition with respect to time and with Dirichlet boundary condition with respect to space variable:

$$
\begin{aligned}
& i \frac{\partial u(t, x)}{\partial t}-\left[t \frac{\partial^{2} u(t, x)}{\partial x^{2}}+t \pi^{2} u(t, x)\right]=f(t, x), 0<t, x<1 \\
& u(0, x)=\frac{1}{3} \mathrm{u}\left(\frac{1}{5}, \mathrm{x}\right)+\varphi(\mathrm{x}), 0<x<1, \\
& u(t, 0)=u(t, 1)=0,0<t<1,
\end{aligned}
$$

where $f(t, x)=-e^{i t} \sin (\pi x), \varphi(x)=\left(1-\frac{1}{3} e^{\frac{i}{5}}\right) \sin (\pi x)$. Exact solution of this problem is $u(t, x)=e^{i t} \sin (\pi x)$. This problem is considered in a Hilbert space $H=L_{2}([0,1])$ of all integrable functions defined on $[0,1]$ equipped with the norm $\|u\|_{[0,1]}=\left(\int_{0}^{1}|u(t, x)|^{2} d x\right)^{1 / 2}$. The time dependent operator $A(u(., x))=-\left[t \frac{\partial^{2} u(., x)}{\partial x^{2}}+t \pi^{2} u(., x)\right], u(., 0)=u(., 1)=0$ is a self-adjoint operator.

In order to obtain numerical approximation of this problem, first of all, first order of accuracy Rothe difference scheme is used as follows: 


$$
\begin{aligned}
& i \frac{u_{n}^{k}-u_{n}^{k-1}}{\tau}-\left[k \tau \frac{u_{n+1}^{k}-2 u_{n}^{k}+u_{n-1}^{k}}{h^{2}}+k \tau \pi^{2} u_{n}^{k}\right]=f\left(t_{k}, x_{n}\right), 1 \leq k \leq N, 1 \leq n \leq M-1, \\
& u_{n}^{0}=\frac{1}{3} u_{n}^{\left[\frac{N}{5}\right]}+\left(1-\frac{1}{3} e^{i / 5}\right) \sin \left(\pi x_{n}\right), 1 \leq n \leq M-1, \\
& u_{0}^{k}=u_{M}^{k}=0,1 \leq k \leq N .
\end{aligned}
$$

Write the difference scheme as

$$
a_{k} u_{n+1}^{k}+b u_{n}^{k-1}+c_{k} u_{n}^{k}+a_{k} u_{n-1}^{k}=f\left(t_{k}, x_{n}\right),
$$

where

$$
a_{k}=-\frac{k \tau}{h^{2}}, b=-\frac{i}{\tau}, c_{k}=\frac{i}{\tau}+\frac{2 k \tau}{h^{2}}-k \tau \pi^{2} .
$$

Hence this system can be written in matrix form as

$$
A U_{n+1}+B U_{n}+A U_{n-1}=D \varphi_{n} 1 \leq n \leq M-1, U_{0}=U_{M}=0,
$$

where

$$
\varphi_{n}=\left[\begin{array}{c}
\varphi_{n}^{0} \\
\varphi_{n}^{1} \\
\ldots \\
\varphi_{n}^{N}
\end{array}\right], \varphi_{n}^{k}=\left\{\begin{array}{c}
\left(1-\frac{1}{3} e^{i / 5}\right) \sin \left(\pi x_{n}\right), k=0 \\
f\left(t_{k}, x_{n}\right), 1 \leq k \leq N
\end{array}\right.
$$

$A(k, k)=a_{k-1}$ for $2 \leq k \leq N+1$, the other entries are zero. $B(1,1)=1$, $B\left(1,\left[\frac{N}{5}\right]\right)=\frac{-1}{3}$, for $2 \leq k \leq N+1, B(k, k-1)=b, B(k, k)=c_{k-1}$ and the other entries are all zero. $D$ is an identity matrix of order $N+1$ and $U_{s}=\left[u_{s}^{0}, u_{s}^{1}, \ldots, u_{s}^{N}\right]^{t}, s=n-1, n, n+1$.

In order to solve the matrix equation (29), a modified Gauss elimination method with respect to $m$ with matrix coefficients is applied as in [5]. Then the results in Table 1 are obtained. 
Table 1. Error with Rothe method

\begin{tabular}{lllll}
\hline & $\mathrm{N}=\mathrm{M}=20$ & $\mathrm{~N}=\mathrm{M}=40$ & $\mathrm{~N}=\mathrm{M}=80$ & $\mathrm{~N}=\mathrm{M}=160$ \\
\hline Error & 0.0178 & 0.0089 & 0.0045 & 0.0023 \\
Relative Error & 0.0252 & 0.0126 & 0.0064 & 0.0032 \\
\hline
\end{tabular}

Secondly, to find an approximate solution of problem (21), (22), (23) Crank-Nicholson difference scheme is applied and the following system is obtained.

$$
\begin{aligned}
& i \frac{k_{n}^{k}-u_{n}^{k-1}}{\tau}-\left[\left(k \tau-\frac{\tau}{2}\right) \frac{1}{2}\left(\frac{u_{n+1}^{k}-2 u_{n}^{k}+u_{n-1}^{k}}{h^{2}}+\frac{u_{n+1}^{k-1}-2 u_{n}^{k-1}+u_{n}^{k-1}}{h^{2}}\right)+\left(k \tau-\frac{\tau}{2}\right) \pi^{2} \frac{1}{2}\left(u_{n}^{k}+u_{n}^{k-1}\right)\right]= \\
& f\left(t_{k}-\frac{\tau}{2}\right), 1 \leq k \leq N, 1 \leq n \leq M-1, \\
& u_{n}^{0}=\frac{1}{3} u_{n}^{\left[\frac{N}{5}\right]}+\left(1-\frac{1}{3} e^{i / 5}\right) \sin \left(\pi x_{n}\right), 1 \leq n \leq M-1, \\
& u_{0}^{k}=u_{M}^{k}=0,1 \leq k \leq N .
\end{aligned}
$$

Write the difference scheme as

$$
e_{k} u_{n+1}^{k-1}+e_{k} u_{n+1}^{k}+f_{k} u_{n}^{k-1}+g_{k} u_{n}^{k}+e_{k} u_{n-1}^{k-1}+e_{k} u_{n-1}^{k}=f\left(t_{k}, x_{n}\right),
$$

where

$$
d_{k}=\left(k \tau-\frac{\tau}{2}\right) \frac{1}{2}, e_{k}=-\frac{d_{k}}{h^{2}}, f_{k}=-\frac{i}{\tau}+\frac{2 d_{k}}{h^{2}}-d_{k} \pi^{2}, g_{k}=\frac{i}{\tau}+\frac{2 d_{k}}{h^{2}}-d_{k} \pi^{2} .
$$

Hence this system can be written in matrix form as

$$
E U_{n+1}+F U_{n}+E U_{n-1}=D \varphi_{n} 1 \leq n \leq M-1, U_{0}=U_{M}=0
$$

where

$$
\varphi_{n}=\left[\begin{array}{c}
\varphi_{n}^{0} \\
\varphi_{n}^{1} \\
\ldots \\
\varphi_{n}^{N}
\end{array}\right], \varphi_{n}^{k}=\left\{\begin{array}{c}
\left(1-\frac{1}{3} e^{i / 5}\right) \sin \left(\pi x_{n}\right), k=0 \\
f\left(t_{k-1 / 2}, x_{n}\right), 1 \leq k \leq N
\end{array}\right.
$$


$E(k, k-1)=e_{k-1}, E(k, k)=e_{k-1}$ for $2 \leq k \leq N+1$, the other entries are zero. $F(1,1)=1, F\left(1,\left[\frac{N}{5}\right]\right)=\frac{-1}{3}$, for $2 \leq k \leq N+1, F(k, k-1)=f_{k-1}$, $F(k, k)=g_{k-1}$ and the other entries are all zero. $D$ is an identity matrix of order $N+1$ and $U_{s}=\left[u_{s}^{0}, u_{s}^{1}, \ldots, u_{s}^{N}\right]^{t}, s=n-1, n, n+1$.

In order to solve the matrix equation (37), a modified Gauss elimination method with respect to $m$ with matrix coefficients is applied as in [5]. Then the results in Table 2 is obtained.

Table 2. Error with Crank-Nicholson method

\begin{tabular}{lllll}
\hline & $\mathrm{N}=\mathrm{M}=20$ & $\mathrm{~N}=\mathrm{M}=40$ & $\mathrm{~N}=\mathrm{M}=80$ & $\mathrm{~N}=\mathrm{M}=160$ \\
\hline Error & 0.0064 & 0.0017 & 0.00043 & 0.00011 \\
Relative Error & 0.0090 & 0.0024 & 0.00061 & 0.00015 \\
\hline
\end{tabular}

\section{Results and Discussion}

In order to find an approximate solution of one dimensional in space variable Schrödinger equation (21) with time dependent self-adjoint operator, with a nonlocal condition (22) in time variable and Dirichlet boundary condition (23) in space variable, first of all first order of accuracy Rothe difference scheme is applied. The error and relative error estimations for $\mathrm{N}=\mathrm{M}=20,40,80$ and 160 are given in Table 1. It is seen from the Table 1 that when the numbers of discretization are doubled error and relative errors become half of the previous one. So in Rothe difference scheme first order convergence is observed. Secondly, second order of accuracy Crank-Nicholson difference scheme is applied. The error and relative error estimations for $\mathrm{N}=\mathrm{M}=20,40$, 80 and 160 are given in Table 2. It is seen from the Table 2 that when the numbers of discretization are doubled, error and relative errors become one fourth of the previous one. So in Crank-Nicholson difference scheme second order convergence is observed. So the results are in line with an article [5]. In the generalization of studies in the 
article [5] to the Schrödinger equation with the time dependent Hamiltonian no difficulty aroused, the results are easily obtained But one of weakness of this study is that under which conditions the semi-group $e^{i \int_{0}^{t} A(s) d s}$ is well defined and the necessary conditions for which the convergences of the integrals exist are not studied. This kind of study is done in an article [6] with Ashyralyev and Hanalyev, for not Schrödinger equations but for parabolic partial differential equations with time dependent operators and this article can be a guide to study semi-group approach for Schrödinger equation with time dependent Hamiltonian. Beside these one important difference of this article from articles [2-4] and [7] is that in this article the Schrödinger equation with time dependent Hamiltonian is studied in an abstract Hilbert spaces. For further studies, the method worked in this article can be generalized to stochastic Schrödinger equation with time dependent Hamiltonian in an arbitrary Hilbert spaces or Banach spaces.

\section{Conclusions}

In this work, in an abstract Hilbert space a linear Schrodinger equation with time dependent self-adjoint operator and with multipoint nonlocal boundary condition is investigated. Existence and uniqueness and stability estimates of this problem is obtained. To obtain an approximate solution of this problem first order of accuracy Rothe difference scheme and second order of accuracy Crank-Nicholson difference scheme are constructed. Stability estimates of these difference scheme are obtained. To support the theory a numerical implementation in one dimension in space is given.

\section{References}

[1] An D., Fang D., and Lin L., Time-Dependent Unbounded Hamiltonian Simulation with Vector Norm Scaling, Quantum 5, 459 (2021), 49 pages. Doi:10.22331/q-2021-05-26-459. 
[2] Berry D. W., Childs A. M., Su Y., Wang X., and Wiebe N., Time-Dependent Hamiltonian Simulation with $L^{1}$-Norm Scaling, Quantum 4, 254, (2020) 40 pages.

[3] Mizrahi S. S., Moussa M. H. Y., and Baseia B., The Quadratic Time-Dependent Hamiltonian: Evolution Operator, Squeezing and Trajectories, International Journal of Modern Physics B, 8 11\&12, (1994) 1563-1576.

[4] Prvanovic S., Operator of Time and Generalized Schrödinger Equation, Advances in mathematical Physics, Article ID: 6290982, (2018) 4 pages. Doi:10.1155/2018/6290982.

[5] Ashyralyev A., and Sirma, A., Nonlocal Boundary Value Problems for the Schrödinger Equation, Computer and Mathematics with Applications 55, (2008) 392-407.

[6] Ashyralyev A., and Hanalyev A., Well-Posedness of Nonlocal Parabolic Differential Problems with Dependent Operators, The Scientific World Journal, Article ID: 519814, (2014) 11 pages. Doi:10.1155/2014/519814.

[7] Kormann K., Holmgren S., and Karlsson H., O., Accurate Time Propagation for the Schrödinger Equation witt an Explicitly Time-Dependent Hamiltonian, The Journal of Chemical Physics 128, 184101 (2008). 11 pages. Doi: 10.1063/1.2916581. 